\title{
Use of Lecture Recordings in Dental Education: Assessment of Status Quo and Recommendations
}

\author{
Zsuzsa Horvath, Ph.D.; Jean A. O'Donnell, D.M.D.; Lynn A. Johnson, M.A., Ph.D.; \\ Nadeem Y. Karimbux, D.M.D., M.M.Sc.; Charles F. Shuler, D.M.D., Ph.D.; \\ Heiko Spallek, D.M.D., Ph.D., M.S.B.A.
}

Abstract: This research project was part of a planned initiative at the University of Pittsburgh School of Dental Medicine to incorporate lecture recordings as standard educational support technologies. The goal of an institutional survey was 1) to gather current data about how dental educators across the United States and Canada use lecture recordings; 2) determine dental educators' perceived value and outcomes of using lecture recordings; and 3) develop recommendations based on \#1 and \#2 for the dental education community. Of the sixty-six North American dental schools at the time of the study, forty-five schools responded to the survey, for a 68 percent response rate. Of the respondents, twenty-eight schools were found to currently conduct lecture recording; these comprised the study sample. This study focused on the dental schools' past experiences with lecture recording; thus, those not currently engaged in lecture recording were excluded from further analysis. The survey questions covered a wide range of topics, such as the scope of the lecture recording, logistics, instructional design considerations, outcomes related to student learning, evaluation and reception, barriers to lecture recording, and issues related to copyright and intellectual property. The literature review and results from the survey showed that no common guidelines for best practice were available regarding lecture recordings in dental education. The article concludes with some preliminary recommendations based on this study.

Dr. Horvath is Director of Faculty Development, Office of Faculty Affairs, University of Pittsburgh School of Dental Medicine; Dr. O'Donnell is Associate Dean for Academic Affairs, and Associate Professor, Department of Restorative Dentistry and Comprehensive Care, University of Pittsburgh School of Dental Medicine; Dr. Johnson is Professor and Dean for Informatics and Innovation, Department of Periodontics and Oral Medicine, University of Michigan School of Dentistry; Dr. Karimbux is Professor and Associate Dean for Academic Affairs, School of Dental Medicine, Tufts University; Dr. Shuler is Dean and Professor, Department of Oral Biology and Medical Sciences, University of British Columbia Faculty of Dentistry; and Dr. Spallek is Associate Dean for Faculty Affairs and Associate Professor, Center for Dental Informatics and Department of Dental Public Health, University of Pittsburgh School of Dental Medicine. Direct correspondence and requests for reprints to Dr. Zsuzsa Horvath, Office of Faculty Affairs, University of Pittsburgh School of Dental Medicine, 3501 Terrace Street, Suite 380A, Pittsburgh, PA 15261; 412-648-9712 phone; 412-648-9960 fax; zshst2@pitt.edu.

Keywords: dental education, educational technology, educational methodology, lectures, lecture recording, podcasts

Submitted for publication 6/18/12; accepted 1/28/13

$\mathrm{R}$ ecording lectures is not a new phenomenon. Students have recorded lectures with lowtech devices for a long time, by taking detailed notes themselves, purchasing transcribed notes from a note-taking service, or using the capabilities of mobile devices, such as laptops equipped with audio recording devices or smart phones. ${ }^{1}$ While high-fidelity recordings were the domain of those who had the knowledge or access to technology in the past, today's mobile technology and technological advancements have made recording so effortless and convenient that the practice has become ubiquitous. ${ }^{2}$ In response to this growing trend, it has become more common for dental schools to provide some form of lecture capture to students. ${ }^{3-5}$ The practice varies widely from school to school, with a small number of institutions systematically recording every lecture and many institutions recording none at all.

In a recent study of undergraduate students in U.S. universities, students rated lecture recording as one of the most useful educational resources available, even higher than face-to-face lectures, learning management systems, notes, or textbooks. ${ }^{6}$ Students report that lecture recording is useful and positive ${ }^{7}$ and see it as an enjoyable learning experience. ${ }^{8}$ In other studies, however, students report that they prefer face-to-face lectures with the option of being able to listen to the lecture recording to enhance notes. ${ }^{8-12}$ In fact, Margaryan et al. demonstrated that students do not have high expectations for the use of technology to enhance learning. ${ }^{13}$ This general attitude is acknowledged in discussion of the Millennial Gen- 
eration. ${ }^{14}$ Students use lecture recording to review course material immediately after the lecture ${ }^{15}$ or later before exams, tests, and quizzes; $;^{5,9,12,15-20}$ to replace face-to-face lecture if they have scheduling conflicts (class is in the early morning, unable to attend); ${ }^{8,10}$ to create better notes; ${ }^{10}$ and to clarify misunderstandings or focus on what faculty members say in face-to-face lectures. ${ }^{9}$ Although students are enthusiastic about lecture recording, they may not realize that relying only on audio content delivery provides less effective learning than reading, as Daniel and Woody point out. ${ }^{21}$ Overall, lecture recording appears to positively affect perceived learning, with students reporting that lecture recording accommodates different learning styles and is especially helpful for non-native speakers, promoting retention. ${ }^{6,20,22,23}$

Prior studies have examined the impact of lecture recording on attendance, which seems to be a major concern of many faculty members. Lecture recording in health science education is prevalent ${ }^{6}$ and is often used when students are not able to attend class. ${ }^{9,10,12}$ Studies have found that lecture recording at the graduate level does not negatively affect attendance, ${ }^{12,17,24}$ and this finding has received support in the literature. ${ }^{16,20,23,25-27}$ Cardall et al. provide a list of reasons students give for attending lectures and also discuss why students might choose replacing class time with personal learning time. ${ }^{11}$ However, Brown reports that lecture recording might negatively influence attendance if the recording merely reproduces the lecture. ${ }^{28}$

At the institutional level, administrators face additional barriers to implementing lecture recording. Meade et al. ${ }^{29}$ and Copley ${ }^{20}$ report that technology concerns in general are responsible for most barriers for both faculty and students, coupled with lack of time for preparation by faculty. ${ }^{23}$ Hew points out that unfamiliarity with podcasts is often a barrier affecting both students and faculty. ${ }^{23}$ Today this concern is largely limited to faculty. However, faculty members must still be prepared to introduce these concepts to uninitiated students. For faculty, unfamiliarity might lead to the lack of insight as to how podcasts can be effectively deployed to enhance learning. Along similar lines, Brittain et al. report that faculty members are not open to new technology unless they can see evidence of the benefits in student learning. ${ }^{5}$ Most successful implementations are coupled with dedicated technical support provided by the institution and strong student involvement for managing the recording, effectively removing this burden from the faculty. ${ }^{5}$
Intellectual property is another issue that can create barriers to implementation and is one that must be addressed at the institutional level. Implications of lecture recording for copyright and privacy issues are only sparingly mentioned in the literature. Zhu and Bergom provide some guidelines and insights to the question, ${ }^{9}$ and Brittain et al. address the balance between accommodating student needs and protecting intellectual property. ${ }^{5}$ Brotherton and Abowd found that copyright was not an issue for instructors when questionable parts of the recordings were edited out, which adds another task for instructors. ${ }^{12}$ Long and Edwards emphasize the importance of dealing with copyright issues from the outset, addressing instructors' concern about intellectual property. ${ }^{30}$

Most studies on lecture recording report the perceived effects on student learning, ranging from improving grades on tests and exams to lowering stress and anxiety by providing lecture recording for review, ${ }^{4-11,19,22-23,25-27,30-33}$ while only two studies have addressed the disadvantages of lecture recording. ${ }^{21,31}$ Despite the large number of articles on the topic, little is known about the effects and implications of lecture recording policies in higher education. As a result, it is unclear what impact, if any, lecture recording has on teaching practices. ${ }^{12,25}$ Brotherton and Abowd collected anecdotal evidence from faculty members about their experience with lecture recording. ${ }^{12}$ In that study, every effort was made not to affect teaching styles with the implementation of lecture recording and support the existing lecturing style with PowerPoint. As a result, instructors changed their teaching styles minimally. However, some faculty members accessed the recording to make sure they were aware of how their material had been presented before or how materials in other courses in the curriculum were presented. A few faculty members started to use class time differently, engaging students in the use of the white board or using the recordings to provide detailed feedback on student presentations. ${ }^{12}$ Reports on individual lecture recording projects also routinely fail to address common problems or suggest an evidence-based best practice approach. When best practices are presented, they have been based entirely on student feedback and do not incorporate feedback from faculty members. ${ }^{8,19}$

The goal of our study was to provide insight into current practices and suggest best practice principles for dental educators and school administrators, based on survey results and suggestions available in the broader educational literature. Studies refer to lecture recording with a variety of terminology: 
podcasts or podcasting, ${ }^{22}$ recorded classroom audio files, ${ }^{22}$ video-recorded lectures, ${ }^{11}$ recorded lecture material, ${ }^{11}$ lecture recording, ${ }^{3}$ lecture capture,${ }^{6,9,31}$ profcast, ${ }^{19}$ videocasts,${ }^{28}$ vodcast,${ }^{25}$ broadcasting, ${ }^{3}$ capture/automated capture, ${ }^{12}$ webcasting,${ }^{18}$ and web lectures. ${ }^{33}$ In this study, we will use the term "lecture recording," allowing for a general use including audio or video recordings. Our assessment addresses the effects of lecture recording on faculty members and their teaching practices as well as the implications of lecture recording for the institution and institutional policies. In the conclusion, we will provide best practice suggestions to the dental education community. We propose these suggestions as a foundation for a broader discussion about the topic, which might lead to a consensus among dental educators.

\section{Methods}

A literature review revealed that there was no suitable and validated instrument for an institutional survey regarding lecture recording. Therefore, we developed our own questionnaire by reviewing the literature for current questions and topics related to lecture recording. After formulating goals in dental education, we developed a draft instrument to assess faculty perception of the effects of lecture recording and institutional support for instructional design and technology. The questionnaire was reviewed by an expert panel that included an expert in dental informatics, two experts in dental education, a leader in technology in dental education, and a dean. An iterative design was used to establish initial validity.

The questionnaire consisted of twenty groups of questions; these ranged from a single yes/no question to a group of yes/no questions, to multiple-choice questions, to questions soliciting open responses about related issues (contact the corresponding author for the instrument). The general topics covered by the instrument included the day-to-day operation of lecture recording, institutional issues (such as the existence of policies and level of support), and the respondent's perception of any change on teaching and learning due to lecture recording. In addition, the survey was designed to develop data on the kinds of technology used for recording lectures, personnel responsible for recording at the operational level, existence of barriers, incentives for recording lectures, and future plans.

We conducted this study between July 2010 and February 2011. The survey was sent to a knowl- edgeable person at each of the then-sixty-six dental schools in North America, such as deans or members of the American Dental Education Association Commission on Change and Innovation in Dental Education (ADEA CCI). These individuals often forwarded the survey request to a faculty member or staff person involved in lecture recording at their school and in a position to answer the questions for their institution. In a few cases, we received more than one survey from an institution; for those, we included the most complete response. We contacted the school representative one time via e-mail. The introduction to the e-mail survey identified the research group, explained the purpose of the survey, and informed the recipient that participation was voluntary. Prior to sending the survey, the University of Pittsburgh Institutional Review Board approved the survey instrument and its mode of distribution (PRO10030585). The participants provided consent by completing the survey questions; they received no compensation but were offered the opportunity to receive a summary of findings.

Results from yes or no questions and multiplechoice questions were quantified. The percentage numbers reported represent the survey participants who answered a particular question. In many cases, percentages do not total 100 percent due to rounding or because multiple answers were possible. Responses to open-ended questions were categorized. Two independent raters classified the responses; after a discussion, both raters agreed on the rating.

\section{Results}

Of the sixty-six North American dental schools contacted, a total of forty-five schools responded (forty-two schools in the United States, three in Canada, and one in Puerto Rico), for a 68 percent response rate. Of the forty-five responding schools, twentyeight (62 percent) reported currently participating in lecture recording. This group of twenty-eight schools comprised our study sample. As this study focuses on past experiences with lecture recording, schools not currently engaged in lecture recording were excluded from further analysis (see Table 1 for a summary of the results).

Regarding the scope of schoolwide lecture recording, 12/28 schools responded that they record almost all lectures, while 16/28 schools only record some lectures. Our survey did not specifically cover occasional lecture capturing, which might be per- 
Table 1. Summary of survey results, by number and percentage of respondents to each question

Topic

Number

Percentage

Scope of lecture recording

record all/almost all didactic courses

$12 / 28$

$16 / 28$

$43 \%$

record only some courses

$27 / 28$

$57 \%$

Incentives for lecture recordings

$96 \%$

Reason why schools implement schoolwide lecture recording policies

$27 / 28$

$96 \%$

Attendance policy

No change in attendance policy

Mandatory attendance

$26 / 27$

$96 \%$

$6 / 27$

$22 \%$

Responsible group for lecture recording

Student-driven

$7 / 26$

$19 / 26$

$11 / 26$

$27 \%$

Staff-driven

$18 / 27$

$73 \%$

Organized at the university level

$42 \%$

Organized at the dental school level

$67 \%$

Distribution of lecture recording

via iTunes

$7 / 26$

$27 \%$

via YouTube

$1 / 26$

$4 \%$

via a Learning Management System

$21 / 26$

$82 \%$

Augmenting recording with Web 2.0 technologies

using technologies varying from RSS feeds to podcasting to blogging

$8 / 26$

$31 \%$

Changes planned for the future

planning changes

$15 / 27$

$55 \%$

Technology used for delivering lecture recording

audio recording

video recordings

$25 / 28$

$19 / 28$

$23 / 28$

audio-synchronized PowerPoint slides

$27 / 28$

$82 \%$

Preparation of faculty

$96 \%$

Observed changes in lecture style since recording started

recording face-to-face lectures

$25 / 27$

prerecording lectures

$14 / 25$

$93 \%$

face-to-face lectures have changed

$9 / 25$

$56 \%$

$11 / 20$

$36 \%$

changes in teaching due to lecture recording

$55 \%$

Change in real or perceived learning by students

not yet measured

$10 / 26$

$39 \%$

changes experienced

$5 / 26$

$19 \%$

Changes in how students evaluate instructor performance

lecture recording has changed how students evaluate instructor performance

$4 / 18$

$12 / 18$

$22 \%$

no change

$2 / 18$

$67 \%$

uncertain

$25 / 28$

$11 \%$

Faculty members' perception of student reception and reactions

$27 / 28$

$89 \%$

Experienced barriers to lecture recording

$96 \%$

Copyright and intellectual property

school retains ownership of recording

$9 / 25$

$12 / 25$

$4 / 25$

$36 \%$

faculty member retains ownership of recording

uncertain about legal status of recording

$48 \%$

$16 \%$

What happens with lecture recordings when a faculty member leaves the institution

recordings stay with institution

recordings stay with faculty member

this issue has not come up

$5 / 27$

$22 \%$

delete or do not reuse the recordings

$1 / 27$

$19 \%$

$4 \%$

(continued) 


\begin{tabular}{|c|c|c|}
\hline Topic & Number & Percentage \\
\hline \multicolumn{3}{|l|}{ Copyright policy } \\
\hline have not adopted special lecture-recording copyright policy & $16 / 27$ & $59 \%$ \\
\hline special copyright policy in place & $9 / 27$ & $33 \%$ \\
\hline uncertain about schoolwide policy & $2 / 27$ & $7 \%$ \\
\hline \multicolumn{3}{|l|}{ Mandatory vs. optional } \\
\hline lecture recording is mandatory & $2 / 27$ & $7 \%$ \\
\hline faculty member can refuse & $23 / 27$ & $85 \%$ \\
\hline \multicolumn{3}{|l|}{ Student privacy } \\
\hline students are visible in recordings & $12 / 27$ & $44 \%$ \\
\hline students not asked to sign release form & $8 / 12$ & $67 \%$ \\
\hline \multicolumn{3}{|l|}{ Change if started over } \\
\hline would change & $10 / 23$ & $44 \%$ \\
\hline would implement changes due to issues with technology & $4 / 23$ & $17 \%$ \\
\hline would change how faculty members are prepared & $8 / 23$ & $35 \%$ \\
\hline would change scope of recordings & $3 / 23$ & $13 \%$ \\
\hline
\end{tabular}

formed by individual faculty members or students on a course, school, or institutional level. We also inquired about the existing incentive structures promoting the effort by faculty members to record or have their lectures recorded. Of the twenty-seven respondents to this question, only one school offered an incentive specific to the use of lecture recording in the form of merit increases. Another school reported incentives for using innovative techniques in the classroom, but not specifically for lecture recording. Regarding the reason why schools began to implement schoolwide lecture recording policies, responses varied. Content analysis was used to categorize the twenty-seven open-ended responses into eleven categories, involving such issues as considerations for student learning, curriculum scheduling, and accommodating faculty members (Table 2). The most common response (fourteen schools) was providing students with the opportunity to review lecture materials in preparation for exams.

Schools that used lecture recordings for remediation provided reasons for that use, such as student participation in rotations scheduled during class time or need for flexibility with curricular scheduling, such as reduced lecture time or more flexible clinical schedules. In addition to the responses mentioned in Table 2, one respondent indicated that the school has used lecture recording as part of its disaster preparedness program: "When the possibility of an H1N1 epidemic arose, we sought to provide faculty members and students the option to stay out of school." Furthermore, one school indicated that another school purchased its recording of a series on the "entire treatment of a patient from diagnosis through adjustment" for complete dentures.

\section{Logistics of Lecture Recording}

According to the respondents, twenty-six out of twenty-seven schools have not implemented or changed attendance policy due to the introduction of lecture recording. Only one respondent answered "yes" to this question but did not provide any further details. Six respondents indicated that attendance was mandatory at their institutions regardless of lecture recordings. One respondent indicated that the school's research showed that attendance increased as a result of recording lectures.

Seven of twenty-six respondents reported that their schools' lecture recordings were student-driven, while in nineteen the school's staff was said to be responsible for recording lectures. Furthermore, eleven of twenty-six respondents reported that lecture recordings are organized at the university level, while eighteen out of seventy-seven said that the recordings are organized entirely at the dental school level. Respondents reported that their schools used different methods to deliver recordings to students. Seven of twenty-six respondents reported that their schools made their recordings available on iTunes, one used YouTube, and twenty-one used some kind of Learning Management System to deliver content to students. A number of respondents indicated that their schools used more than one mechanism for delivering recorded lectures. None reported that 
Table 2. Categorized responses to survey question "Why did you start recording lectures?"

\begin{tabular}{lcc} 
Response Category & Number & Percentage \\
\hline Provide students with opportunity to review in preparation for exams & 14 & $52 \%$ \\
Students demanded & 7 & $26 \%$ \\
Helping students who miss class for educational reasons & 6 & $22 \%$ \\
Recording allows for using class time differently & 3 & $11 \%$ \\
Archiving courses & 3 & $11 \%$ \\
Remediation & 2 & $11 \%$ \\
Offering lectures remotely & 2 & $7 \%$ \\
Faculty calibration & 1 & $7 \%$ \\
Helping faculty members if they miss class for continuing educational reasons & 1 & $4 \%$ \\
Reducing contact hours & 1 & $4 \%$ \\
Faculty request & $4 \%$ \\
Note: Multiple selections were allowed. & & \\
\hline
\end{tabular}

their school made its recordings available publicly. Augmenting recording with Web 2.0 technology was an additional option for some of the respondents, with eight of twenty-six schools using technologies varying from RSS feeds to podcasting to blogging. One respondent identified lack of faculty readiness as a reason for not implementing Web 2.0 technologies at his or her school.

Considering the ever-changing nature of technology, fifteen of twenty-seven respondents indicated that their schools were planning changes regarding lecture recording in the future; these changes principally involved the incorporation of new technology and building infrastructure. Due to the rapid changes in technology, we are not reporting the particular technology that the respondents said was used; however, the respondents indicated the following technology was used for delivery: twenty-five respondents said their schools provided audio recordings to their students; nineteen provide video recordings; and twenty-three provide audiosynchronized PowerPoint slides. Several respondents reported that their schools used more than one kind of technology.

\section{Instructional Design Considerations}

Representatives from twenty-seven of twentyeight schools responded to the question of how faculty members were prepared for the lecture recordings. The extent and level of preparation varied greatly among these schools, from notification about the technology to organized training, from individual consultation to group tutorials, and from basic technical to specialized instructional technology support. Content analysis was used to categorize the twenty-seven open-ended responses into nine categories (Table 3). Of note, respondents from thirteen schools reported that a formal tutorial or training was provided, while only seven reported that no preparation was provided for faculty members engaged in lecture recording.

In addition, representatives from twenty-five of twenty-seven schools indicated that they recorded face-to-face lectures, while fourteen prerecorded lectures. Representatives from nine of twenty-five schools reported that their face-to-face lectures have changed in frequency or otherwise following the introduction of lecture recording. Some of the responses to this question (and reasons for starting to record lectures) indicated that as a result of lecture recording, class time was used for active learning activities such as application of knowledge or problem-solving. A related question was asked about any changes in faculty teaching style to take advantage of the new technology. Representatives from eleven of twenty responding schools said that their faculty members had changed their teaching to take advantage of lecture recording. These changes included providing supplemental materials, changing lecture formats, focusing on case and problem integration, incorporating more video, changing from slides to PowerPoint presentations, avoiding statements in lectures that cannot be supported, staying current with the material, and assigning students to view lecture recording prior to class. 
Table 3. Categorized responses to survey question "How were faculty members prepared for the lecture recordings, if at all?"

\begin{tabular}{lcc} 
Response Category & Number & Percentage \\
\hline Tutorial or training & 13 & $48 \%$ \\
No preparation & 7 & $26 \%$ \\
Technical support & 5 & $19 \%$ \\
Instructional design support & 4 & $15 \%$ \\
Student assistance in class & 3 & $11 \%$ \\
Individual support & 3 & $11 \%$ \\
Faculty members were informed & 2 & $7 \%$ \\
Instructional technology support & 2 & $7 \%$ \\
Automated process; faculty members do not have to do anything & 1 & $4 \%$ \\
Note: Multiple selections were allowed. &
\end{tabular}

\section{Outcomes}

One of the questions about outcomes related to a noticeable change in real or perceived learning by students. Ten of twenty-six respondents said their schools had not yet measured the changes in real or perceived learning by students, while five reported that their school had experienced changes in real or perceived learning. These changes included student appreciation of recordings when preparing for tests and exams, reduced stress, improved performance on exams (which might be also due to other factors), and increased student satisfaction. In one school, the respondent noted that attendance decreased while test scores remained high. In another school, the respondent reported that students believed recordings did not replace live lectures and the opportunity to ask questions and engage in classroom discussion.

Another question on outcomes concerned changes in how students evaluate instructor performance. Four of eighteen respondents reported that lecture recording had changed how students evaluate instructor performance at their schools, while twelve indicated that their evaluations had not changed and two were uncertain of any changes. The next question examined how faculty members perceive student reception and reactions. Twenty-five of twenty-eight respondents answered this question and had highly variable responses. Content analysis was used to organize the twenty-five open-ended responses into nine categories (Table 4). While overall eight school representatives reported that they felt their students appreciated lecture recording, many others reported a mix of negative student perceptions.

\section{Barriers, Copyright, and Lessons Learned}

Content analysis was used to organize the twenty-seven open-ended responses into eight categories to the question regarding barriers schools experienced (Table 5). The most common barriers to lecture recoding noted by school representatives

Table 4. Categorized responses to survey question “How do faculty members perceive student reception/reactions?"

\begin{tabular}{|c|c|c|}
\hline Response Category & Number & Percentage \\
\hline Students appreciate recording & 8 & $32 \%$ \\
\hline No evaluation & 4 & $16 \%$ \\
\hline Students complain if lectures are not recorded & 3 & $12 \%$ \\
\hline Students have mixed reactions & 3 & $12 \%$ \\
\hline Students believe they will face attendance issues & 3 & $12 \%$ \\
\hline Students prefer face-to-face lectures & 2 & $8 \%$ \\
\hline Students do not find recordings useful & 2 & $8 \%$ \\
\hline Students perceive lecture recording as standard practice & 1 & $4 \%$ \\
\hline Students show resistance to technology-based teaching & 1 & $4 \%$ \\
\hline
\end{tabular}


Table 5. Categorized responses to survey question "What barriers have you experienced?"

\begin{tabular}{lcc} 
Response Category & Number & Percentage \\
\hline Faculty resistance & 18 & $67 \%$ \\
Technology issues & 5 & $19 \%$ \\
Intellectual property & 4 & $15 \%$ \\
Losing attendance & $3 \%$ & $11 \%$ \\
No flexible schedule & 1 & $4 \%$ \\
Resources & 1 & $4 \%$ \\
Communication & 1 & $4 \%$ \\
Cost of license & 1 & $4 \%$ \\
Note: Multiple selections were allowed. &
\end{tabular}

were faculty resistance, problems with technology, questions of intellectual property, and fear of decreasing attendance.

Several questions were asked regarding copyright and intellectual property. Nine of twenty-five respondents reported that their schools retained ownership of the recordings, while twelve reported that faculty retain ownership and four were uncertain about the legal status of their lecture recordings. Given that dental educators transition between different institutions throughout their academic career, an important question is about intellectual property and what happens when a faculty member leaves the institution; the next question addressed that situation. The twenty-seven responses were organized into five categories: twelve respondents reported that the recordings stay with the institution and two reported that they stay with the faculty member. Six claimed this issue had not come up by the time of the survey, and five said they deleted or did not reuse the recordings. One respondent was uncertain about what happens with the recordings at that school.

There were twenty-seven respondents to the question regarding copyright policy. Of those, sixteen said their schools had not adopted a special lecture recording copyright policy, nine had a special copyright policy in place, and two were uncertain about a schoolwide policy. Representatives from two of twenty-seven schools reported that lecture recording is mandatory (faculty members cannot opt out), and twenty-three reported that faculty members can refuse to be recorded in the classroom. When it comes to the privacy of the students, twelve of twenty-seven respondents indicated that students at their schools are visible in the recordings; of these schools, eight do not ask students to sign a release form.

Finally, representatives from ten of twentythree schools said they would not change anything if they could start all over. On this question, four reported that they would implement changes due to issues with technology, while eight would change how they prepare faculty members and three would change the scope of the recordings.

\section{Discussion}

Lecture recordings are becoming more common in dental education, following a general trend in higher education; ${ }^{6}$ nevertheless, practices, procedures, and policies vary. While the Commission on Dental Accreditation (CODA) has a standard regarding the use of educational technology, it does not specify how lectures or other educational experiences should be delivered to students. This situation results in a wide variation reflected in the motivations for why dental schools implement lecture recordings. Based on the results of our study, the primary motivation for initiating lecture recording is grounded in student demand, followed by reasons such as perceived value of lectures, remediation preparation, student absenteeism, and establishment of a studentcentered learning approach.

Upon reflection, some respondents to our survey indicated that there were issues they did not consider during the implementation phase at their school, such as decisions about selection of the most suitable technology and the appropriate setup for their individual needs. For instance, five of the respondents (22 percent) expressed concern with establishing the proper infrastructure right from the start in order to avoid changes after the initial implementation; others questioned the scope of the recording, such as whether to record all courses or implement automatic recordings to remove the technological burden from faculty members. Our results also indicate that some 
school administrators failed to secure unequivocal buy-in from faculty members when introducing new technology. However, it is notable that, in most of the schools in our study, faculty members are able to opt out of lecture recording.

In planning and implementing lecture recordings, many schools have not addressed instructional design considerations, according to our results. The assessment of teaching effectiveness and outcomes in learning of systematic lecture recording in dental education is scarce. ${ }^{5}$ In addition, better instructional preparation of faculty members and an easy-to-use technological setup were the most commonly cited areas where respondents said their schools were planning to adapt their current approaches. It is important to recognize that lecture recording, by itself, is not going to improve teaching effectiveness any more than other instructional tools and that the key factor to learning is the design of the instruction. Thus, it would be beneficial to investigate how recorded lectures can be used to design better instruction. A possible question for future investigation could be whether instructors are able to improve their lectures on their own by simply reviewing the recording or if they need to work with an educational specialist.

A recurring theme among our respondents and in the literature is a concern about how lecture recording affects class attendance. This might be especially relevant to health professions education, where skills and nuances of practice might be better discussed face-to-face. The fear of decreasing attendance often contributes to faculty resistance to offer lecture recordings. Although many schools require mandatory attendance regardless of recording, the solution to this question may not lie in enforcing an attendance policy, but in how the face-to-face class time is used. Contrary to other survey results, ${ }^{16}$ our findings suggest that faculty members change their teaching due to the new technology. As indicated by some respondents (36 percent), a good practice is to use lecture recordings outside the classroom and utilize class time for activities that promote studentcentered learning and higher level thinking skills as reported in other studies. ${ }^{8,15,23,33,34}$ In addition, many schools offer lecture recording as a solution to scheduling conflicts and support students who are not able to attend class as also noted in the literature. ${ }^{9,10,12,17}$ Our results confirm what other studies have found regarding changing student expectations as a result of systematic lecture recordings inasmuch as students express negative evaluations if recordings were missing. ${ }^{16}$ Study respondents have reported general resistance to change, ${ }^{35}$ copyright violations, anticipated student procrastination, and anxiety about technology failures as barriers to recording lectures.

\section{Recommendations for Best Practices}

As other studies have emphasized, ,9,10,21 our results do not suggest that lecture recording can or should replace a carefully designed, active learning experience provided in a face-to-face classroom, but instead that offering recorded lectures to students can serve as a supplement to the classroom experience. Currently, academic dental institutions attempt to use lecture recordings to enhance the learning opportunities for students in their curricula, but it appears that no evidence-based, best practice guidelines have yet evolved. Our study can prompt a first draft of such guidelines based on our survey results and a literature review. Important considerations prior to the use of lecture recording can be defined in the following key areas: instructional goals, allowing sufficient time for preparation, adhering to copyright and intellectual property laws, establishing dedicated IT support, faculty review of recordings prior to their release, combining recordings with other class time activities, referring to the recordings in class, leaning towards shorter and more meaningful pieces instead of full-lecture recording, and requesting feedback via student evaluations. We have organized our recommendations into several categories:

\section{Preparation at Institutional Level}

- Provide technical and instructional support and training for faculty. ${ }^{5}$

- Establish institutional strategy and long-term plans for lecture recording. ${ }^{5}$

\section{Technology}

- Have a back-up plan. ${ }^{8}$

- Use the smallest and fastest format (frame rate and frame resolution) for easy and high-quality download. ${ }^{8,36}$

- Use automated recording systems. ${ }^{9}$

- Check and experiment with recording quality. ${ }^{9}$

- Create an easily searchable (by topic and by date) archive of lectures..$^{10,15}$

- Provide one single source of lecture recordings. ${ }^{5}$

- Set up a notification system or subscription service. $^{5}$ 
- Offer opt-out option if possible: "mute button during lecture," "privacy zones where audio/video is not being recorded." 12

- Provide faculty members with portable microphone so lecturers are not bound to podium.

- Advise faculty members to repeat questions from students. ${ }^{4}$

- Offer different speed options for review by students. $^{4}$

- Provide faculty members with telestrator instead of laser provision for drawing; ${ }^{4}$

- Ensure that slides are clear in the video podcast. ${ }^{20}$

Instructional Design

- Set clear instructional goals for the purpose of lecture recording. ${ }^{9}$

- Provide clear instructions for how to access the lecture recording. ${ }^{8,9}$

- Do not assume all students are computer-literate: offer training for students.

- Consider and address different learning styles (auditory and visual). ${ }^{8,35,37}$

- Consider format: restructure content and delivering in smaller segments, provide a summary of the lecture instead of live lecture recording, or assign viewing recording to the students prior to the class (promotes active learning). ${ }^{8,15,18,23,33,34}$

- Consider impact on the curriculum: schools cannot expect students to listen to a full complement of lectures and still come to all the classes during the term.

- Integrate lecture recording with other content and activities inside and outside of the classroom. $8,9,28,33,34,38,39$

- Provide answers to the most frequently asked questions (weekly or biweekly basis). ${ }^{15}$

- Provide incentives for students to come to class by using class time for active learning and interactive activities. ${ }^{9,25}$

- Use lecture recording to provide supplementary materials to your course (summaries or additional materials). ${ }^{27}$

- Refer to the lecture recording in class. ${ }^{9}$

- Offer audio review sessions to students before tests and quizzes by creating an audio file with questions. ${ }^{15}$

- Obtain feedback and evaluate usage: self-reporting, observation, tests, records/access logs, focus groups. ${ }^{5,15}$

- Give prompt feedback to students; return assignments in a timely manner.

- Make it dynamic by using social media and realtime information. ${ }^{40}$
- Allow students to create podcasts. ${ }^{27}$

\section{Copyright and Privacy}

- Consider different delivery options: passwordprotected environment available only to a class (e.g., LMS, iTunesU), school, university (e.g., iTunesU), or the public (e.g., iTunesU) versus public websites (YouTube). ${ }^{9}$

- If the recordings are posted publicly, obtain copyright clearance, signed consent, and release forms according to your school policy. ${ }^{9}$

- Only record lecturer and try to omit students.

- Establish policy that prohibits students from sharing recordings with anyone else.

- Keep all recordings in password-protected area to retain Fair Use status. ${ }^{41}$

\section{Conclusion}

Our study of the current status of lecture recording in North American dental schools showed that providing recorded lectures to dental students is becoming more common. However, it is also clear that there are no widely accepted guidelines, so many institutions experience the same barriers to implementation. Dental schools that do not offer lecture recording, or are considering modifying existing recording policies, would benefit from a set of guidelines from needs assessment to implementation. Some schools may struggle with the decisions and the resources of producing a curriculum to suit all the students' needs. This article provides a first step in this process by collecting recommendations for best practices based on a review of the literature and the survey results.

Further research is needed regarding teaching effectiveness and outcomes in learning through systematic or occasional lecture recording in dental education. Future studies should also try to gauge whether delivering curriculum content in this format really does affect student learning. Perhaps faculty members and schools need to create a library of recorded videos that students can view prior to classes and, as is advocated by such programs as Khan Academy, use class time to answer questions or solve problems based on lecture content.

\section{Acknowledgments}

The authors would like to express their gratitude to all individuals from all participating schools who completed our survey. We would also like 
to thank these individuals, all at the University of Pittsburgh: Shannon Valenti, Regulatory Compliance Facilitator at Clinical and Translational Science Institute, for her assistance in the IRB submission process; Rebecca Abromitis, M.L.S., Reference Librarian at the Health Sciences Library System, for her extensive help with the literature review; Michael Dziabiak, M.A., Research Assistant at the Center for Dental Informatics, for his help with managing the literature review process; and Anh Nguyen, student, for data tabulation. We also thank Dr. Seth Weinberg, faculty member at the University of Pittsburgh School of Dental Medicine, for his advice during the writing process.

\section{REFERENCES}

1. Boynton JR, Johnson LA, Nainar SM, Hu JC. Portable digital video instruction in predoctoral education of child behavior management. J Dent Educ 2007;71(2):545-9.

2. Johnson L, Smith R, Willis H, Levine A, Haywood K. The 2011 horizon report. Austin: New Media Consortium, 2011.

3. Schleyer TK, Thyvalikakath TP, Spallek H, Dziabiak MP, Johnson LA. From information technology to informatics: the information revolution in dental education. J Dent Educ 2012;76(1):134-45.

4. Craig, JF, Trotman CA, Gilliam J. Use on instructional technology, University of Maryland Dental School. Panel discussion at meeting of American Dental Education Association Commission on Change and Innovation in Dental Education (ADEA CCI), Cambridge, MA, June 2010.

5. Brittain S, Glowacki P, Ittersum JV, Johnson L. Podcasting lectures: formative evaluation strategies helped identify a solution to a learning dilemma. Educause Q 2006;29(3):24-31.

6. Echo 360, Feedback Loop Student Survey Program. Capturing student perspectives about lecture recordings. Dulles, VA: Echo 360, 2010. At: www.echo360.com/pdf/ Echo360_CSPALR_whitepaper.pdf. Accessed: June 14, 2012.

7. Bolliger DU, Supanakorn S, Boggs C. Impact of podcasting on student motivation in the online learning environment. Comput Educ 2010;55(2):714-22.

8. McCombs S, Liu Y. The efficacy of podcasting technology in instructional delivery. Int J Technol Teach Learn 2007;3(2):123-34.

9. Zhu E, Bergom I. Lecture capture: a guide to effective use. CRLT Occasional Papers, University of Michigan, 2010. At: www.crlt.umich.edu/publinks/CRLT_no27.pdf. Accessed: June 14, 2012.

10. McKinney D, Dyck JL, Luber ES. iTunes university and the classroom: can podcasts replace professors? Comput Educ 2009;52(3):617-23.

11. Cardall S, Krupat E, Ulrich M. Live lecture versus videorecorded lecture: are students voting with their feet? Acad Med 2008;83(12):1174-8.
12. Brotherton JA, Abowd GD. Lessons learned from eClass: assessing automated capture and access in the classroom. ACM T Comput Hum Int 2004;11(2):121-55.

13. Margaryan A, Littlejohn A, Vojt G. Are digital natives a myth or reality? University students' use of digital technologies. Comput Educ 2011;56(2):429-40.

14. Oblinger D, Oblinger J. Is it age or IT: first steps toward understanding the net generation. In: Oblinger D, Oblinger J., eds. Educating the net generation. Boulder, CO: Educause, 2005:12-31. At: http://net.educause.edu/ir/library/ pdf/pub7101.pdf. Accessed: June 11, 2012.

15. Guertin LA. Creating and using podcasts across the disciplines. Currents Teach Learn 2010;2(2):4-12.

16. Lonn S, Teasley SD. Podcasting in higher education: what are the implications for teaching and learning? Internet Higher Educ 2009;12(2):88-92.

17. Nast A, Schäfer-Hesterberg G, Zielke H, Sterry W, Rzany B. Online lectures for students in dermatology: a replacement for traditional teaching or a valuable addition? J Eur Acad Dermatol Venereol 2009;23(9):1039-43.

18. Reynolds PA, Mason R, Eaton KA. Webcasting: casting the web more widely. Br Dent J 2008;204(3):145-9.

19. Sandars J. Twelve tips for using podcasts in medical education. Med Teach 2009;31(5):387-9.

20. Copley J. Audio and video podcasts of lectures for campus-based students: production and evaluation of student use. Innov Educ Teach Int 2007;44(4):387-99.

21. Daniel DB, Woody WD. They hear, but do not listen: retention for podcasted material in a classroom context. Teach Psychol 2010;37(3):199-203.

22. Greenfield S. Podcasting: a new tool for student retention? J Nurs Educ 2011;50(2):112-4.

23. Hew KF. Use of audio podcast in K-12 and higher education: a review of research topics and methodologies. Educ Technol Res Dev 2009;57(3):333-57.

24. Pilarski PP, Johnstone DA, Pettepher CC, Osheroff N. From music to macromolecules: using rich media/podcast lecture recordings to enhance the preclinical educational experience. Med Teach 2008;30(6):630-2.

25 . Heilesen SB. What is the academic efficacy of podcasting? Comput Educ 2010;55(3):1063-8.

26. Kardong-Edgren S, Emerson R. Student adoption and perception of lecture podcasts in undergraduate Bachelor of Science in nursing courses. J Nurs Educ 2010;49(7):398401.

27. McGarr O. A review of podcasting in higher education: its influence on the traditional lecture. Australas J Educ Technol 2009;25(3):309-21.

28. Brown M. Learning and technology: "in that order." Educause Rev 2009;44(4):62-3.

29. Meade O, Bowskill D, Lymn JS. Pharmacology podcasts: a qualitative study of non-medical prescribing students' use, perceptions, and impact on learning. BMC Med Educ 2011;11(2).

30. Long SR, Edwards PB. Podcasting: making waves in millennial education. J Nurses Staff Dev 2010;26(3):96-101.

31. Chu LF, Young CA, Ngai LK, Cun T, Pearl RG, Macario A. Learning management systems and lecture capture in the medical academic environment. Int Anesthesiol Clin 2010;48(3):27-51. 
32. Walmsley AD, Lambe CS, Perryer DG, Hill KB. Podcasts: an adjunct to the teaching of dentistry. Br Dent $\mathbf{J}$ 2009;206(3):157-60.

33. Day J, Foley J. Evaluating web lectures: a case study from HCI. In: Olson G, Jeffries R. Proceeding CHI '06 extended abstracts on human factors in computing systems. New York: ACM, 2006:195-200.

34. Koller D. Death knell for the lecture: technology as a passport to personalized education. New York Times, December 5, 2011. At: www.nytimes.com/2011/12/06/ science/daphne-koller-technology-as-a-passport-topersonalized-education.html?pagewanted=all. Accessed: June 11, 2012.

35. Vogt M, Schaffner B, Ribar A, Chavez R. The impact of podcasting on the learning and satisfaction of undergraduate nursing students. Nurse Educ Pract 2010;10(1):38-42.

36. Lane C. Podcasting at the UW: an evaluation of current use. Office of Learning Technologies, University of Washington, 2006. At: www.washington.edu/lst/research/ papers/2006/podcasting_report.pdf. Accessed: June 11, 2011.
37. Maag M. Podcasting: an emerging technology in nursing education. In: Park HA, Murray P, Delaney C, eds. Consumer-centered computer-supported care for healthy people. Amsterdam: IOS Press, 2006:835-6.

38. Parry M. Killing the lecture with technology, part II. Chronicle of Higher Education, August 17, 2010. At: http://chronicle.com/blogs/wiredcampus/killing-thelecture-with-technology-part-ii/26269. Accessed: June 11, 2012.

39. Parson V, Reddy P, Wood J, Senior C. Educating an iPod generation: undergraduate attitudes, experiences, and understanding of vodcast and podcast use. Learn Media Technol 2009;34(3):215-28.

40. Masoni M. Why online education needs to get social. Mashable Social Media. At: http://mashable. com/2010/08/06/online-education-social/. Accessed: June $11,2012$.

41. Spallek H, Schleyer TK. Educational implications for copyright in a digital world. J Dent Educ 1999;63(9):67381. 